\title{
O conceito de experiência e a formação para a democracia numa perspectiva Deweyana
}

\author{
Altair Alberto Fávero* \\ Universidade de Passo Fundo \\ Diego Bechi** \\ Prefeitura Municipal de Tapejara
}

Resumo O presente ensaio tem por escopo analisar o conceito deweyano de experiência no processo de formação de uma sociedade democrática. Para tanto, iniciamos mostrando que a filosofia da educação desenvolvida por John Dewey (1859-1952) se assentou numa teoria da experiência estruturada em torno de propósitos, fundamentos epistemológicos e métodos potenciais para proporcionar o aprimoramento das habilidades de raciocínio e do espírito crítico dos educandos. Na nossa interpretação, tais elementos são imprescindíveis para constituir uma educação democrática, pois para Dewey, a democracia não se limita a um regime de governo, mas sim é um modo de vida compartilhado e a sociedade torna-se democrática quando os diferentes grupos sociais são capazes de intercambiar experiências entre si de modo livre e plural.

PALAVRAS-CHAVE: John Dewey; Educação democrática; Experiência; Processo formativo. 


\title{
The concept of experience and the formation for the democracy in a Deweyan perspective
}

\begin{abstract}
The scope of the present essay is to analyze the deweyan concept of experience in the formation process of a democratic society. Therefore we started showing that the educational philosophy developed by John Dewey (1859-1952) settled in a theory of experience structured around purposes, epistemological fundaments and potencial methods to provide the improvement of reasoning skills and critic spirit of students. In our interpretation, such elements are essentials to build a democratic education, because to Dewey, the democracy is not limited in a government regime, but it's a shared way of life and the society becomes democratic when different social groups are able to exchange experiences with each other in a free and plural mode.
\end{abstract}

KEYWORDS: John Dewey; Democratic education; Experience; Formative process.

\section{Introdução}

A filosofia da educação desenvolvida por Dewey se assentou em uma teoria da experiência estruturada em torno de propósitos, fundamentos epistemológicos e métodos com vistas a propiciar o desenvolvimento das habilidades de raciocínio e espírito crítico dos educandos. A formação para a liberdade intelectual e moral do jovem requer, na perspectiva pensada por Dewey (1979), a construção de um sistema educacional comprometido com a qualidade da experiência. Não há dúvidas de que a escola é um espaço onde se produz constantemente novas experiências. No entanto, habitualmente as práticas constituídas no ambiente escolar têm proporcionado experiências defeituosas e sem valor educativo, restringindo o crescimento contínuo, as possibilidades de futuras experiências mais ricas e sua potencialidade educativa.

Em Experiência e educação, Dewey (1979, p. 14) afirma: "a crença de que toda educação genuína se consuma através de experiência não quer dizer que todas as experiências são genuínas e igualmente educativas. Experiência e educação não são termos que se equivalem. Algumas experiências são deseducativas". Por conta disso, a escola precisa rever seus propósitos e métodos educacionais - calcados, sobretudo, na imposição de saberes - e utilizar suas condições físicas e sociais para delas extrair os elementos que possam viabilizar aos jovens o processamento de experiências efetivamente educativas. A responsabilidade primária do educador é reconhecer as situações que os levem ao processamento de experiências saudáveis, largamente acessíveis e capazes de satisfazer os amplos anseios humanos.

No presente ensaio, nossa intenção é analisar o conceito deweyano de experiência no processo de formação de uma sociedade democrática. Trata-se de um estudo teórico bibliográfico, de cunho hermenêutico, que busca nas obras Experiência e Educação (1979), Democracia e Educação (1959a) e Como Pensamos (1959b) os 
argumentos deweyanos de uma teoria da experiência necessária para construir uma sociedade democrática. Para haver a construção de experiências democráticas e propiciar uma forma de interação mais livre são necessários dois elementos: reconhecer a interpenetração mútua de interesses recíprocos como fator de regulação e direção social; e, estabelecer mudança nos hábitos sociais a partir das novas situações criadas pelos vários intercâmbios e da cooperação mais livre entre os diferentes grupos sociais.

\section{A construção de experiências reflexivas}

A concepção pragmática deweyana de educação possui os fundamentos necessários à construção de uma educação democrática e a formação de docentes aptos a atuar de forma reflexiva. Logo no início da obra Experiência e educação Dewey faz uma distinção entre a educação tradicional e a educação progressiva. Segundo ele (1979, p. 05), "o surto do que se chama de educação nova e escola progressiva é ele próprio o resultado do descontentamento com a educação tradicional". A crítica ao antigo modelo é direcionada aos esquemas de imposição de padrões, conhecimentos e métodos. $\mathrm{Na}$ escola tradicional o ato do ensinar e do aprender resume-se ao momento da aula expositiva, ao passo que no modelo pragmático deweyano o processo de ensino e aprendizagem não se limita à simples exposição e memorização de conteúdos: visa ao desenvolvimento da capacidade de raciocínio e espírito crítico dos educandos. Dewey também faz essa distinção no sexto capítulo de Democracia e educação ao propor um modelo de educação calcado no conceito de experiência, contrapondo-o aos moldes da educação conservadora. Esta última, ao inibir a formação de faculdades existentes no espírito, não desenvolve as potencialidades humanas necessárias à construção de uma nova sociedade. Por sua vez, a educação progressiva se esforça "por modelar as experiências dos jovens de modo que, em vez de reproduzirem os hábitos dominantes, venham a adquirir hábitos melhores, de modo que a futura sociedade adulta seja mais perfeita as suas próprias sociedades atuais"(Dewey 1959a, p. 85).

Ao se posicionar a favor do conceito de "escola ativa", Dewey defendeu que o aluno deve ter iniciativa, originalidade e precisa agir de forma cooperativa. Cabe ao professor dirigir o ensino no sentido de estimular o pensamento reflexivo por meio de situações que despertem e favoreçam o fluxo de ideias. O desafio é superar o modelo tradicional, que, de acordo com Dewey (1979, p. 05), "é, em essência, esquema de imposição de cima para baixo e de fora para dentro". Para o filósofo, a escola nova ou progressiva teria como base a igualdade entre professor e aluno, fazendo do ambiente escolar um espaço livre, a fim de promover o senso crítico do aluno por meio de um processo interativo, deixando de ser um movimento de cima para baixo, como ocorria na pedagogia tradicional. Contudo, para a aula se tornar interativa e reflexiva o professor deveria obter as habilidades e as competências que o tornasse apto a exercer essa nova proposta pedagógica, isto é, para proporcionar uma prática pedagógica reflexiva o professor deveria ser reflexivo. Em tese, Dewey (1959b, p. 63) afirmava que

o problema de método na formação de hábitos de pensamento reflexivo é o problema de estabelecer condições que despertem e guiem a curiosidade; de preparar nas coisas experimentadas, as conexões que, ulteriormente, promovam o fluxo de sugestões, criem problemas e propósitos que favoreçam a consecutividade na sucessão de ideias. 
Conforme salientado anteriormente, o professor reflexivo assume a função de criar estratégias pedagógicas que instiguem os alunos a serem agentes produtores de conhecimentos. Mas, para isso, ele precisa superar o modelo de ensino centrado na transmissão de informações. Em análise a essa mesma problemática, no décimo segundo capítulo de Democracia e educação Dewey traz à tona importantes considerações acerca dos pressupostos metodológicos compatíveis ao fomento de experiências educativas ligadas ao desenvolvimento da capacidade de pensar, à produção de conhecimentos e a construção de uma sociedade democrática. Em relação a isso, ele (1959a, p. 167) direciona uma crítica à pedagogia tradicional ao afirmar que "os conhecimentos informativos separados da ação reflexiva são conhecimentos mortos, peso esmagador para o espírito. Como simulam os verdadeiros conhecimentos, segregam o veneno do preconceito, e são poderosos obstáculos para o ulterior desenvolvimento da inteligência". Dito de outro modo, a mera aquisição de palavras mediante o auxílio de práticas e materiais condizentes com a metodologia passiva - por fornecer soluções já prontas às atividades realizadas - não propicia as condições adequadas ao eficaz desenvolvimento da reflexão, como também embaraça o raciocínio.

O aprimoramento das faculdades de espírito depende exclusivamente de situações que suscitem a reflexão. Em observância a essa problemática, Dewey (1959a, p. 167) defendeu que "o único caminho direto para o aperfeiçoamento duradouro dos métodos de ensinar e aprender consiste em centralizá-los nas condições que estimulam, promovem e põe em prova a reflexão e o pensamento". O processo de ensino e aprendizagem não pode limitar suas funções às tradicionais técnicas de ler, ouvir e reproduzir aquilo que foi dito e lido. Não há dúvida quanto à relevância da leitura e da escuta no decorrer do processo formativo, porém faz-se necessário propiciar algumas mudanças nos propósitos pelos quais vêm sendo utilizadas. A substituição do "repetir" e do "reproduzir" pelo "fazer" constitui uma das iniciativas metodológicas mais eficientes em favor da reflexão. Diante dessas transformações, a problematização passa a ser valorizada em detrimento da inculcação e memorização de conteúdos. As atividades escolares elaboradas com o auxílio de questões e problemas a serem resolvidos pelos próprios alunos incentivam o surgimento de experiências reflexivas. Assim descreveu o autor (1959a, p. 169): "todos esses métodos dão aos alunos alguma coisa para fazer e não alguma coisa para aprender; e o ato de fazer é de tal natureza que exige a reflexão ou a observação intencional das relações; daí, naturalmente, resulta aprendizagem". Contudo, a técnica pessoal do professor é insuficiente se a instituição de ensino não contar com bons materiais, aparelhos e uma estrutura que favoreça tais iniciativas.

Para compreender a origem e a função do pensar reflexivo na edificação de uma educação democrática faz-se necessária a junção de uma nova e importante premissa às considerações até então apresentadas. Em síntese, a experiência representa, na teoria deweyana, o estágio inicial do ato de pensar. Nesse sentido, torna-se relevante encontrar uma definição satisfatória do conceito de pensar. Para Dewey (1959a, p. 165), "pensar é o ato cuidadoso e deliberado de estabelecer relações entre aquilo que se faz e as suas consequências". Pelo pensamento as pessoas conseguem prever as consequências e determinar a significação de algum ato realizado ou a se realizar. O esforço de pensar e o uso do raciocínio dão origem a experiências significativas. A experiência é, de modo geral, uma ação ativo-passiva: o sujeito age sobre o objeto da experiência 
transformando-o e, consequentemente, sendo por ele transformado. $\mathrm{O}$ processo de ação e reação, resultante da relação entre o sujeito pensante e o ambiente, constitui a multiplicidade de experiências que orientam e atribuem sentido ao agir humano. Diferentemente de outros elementos da natureza (físicos, químicos, orgânicos), cujos corpos agem uns sobre os outros, modificando-se reciprocamente, sem apresentar nenhum sentido de adaptação, o ser humano é o único ser vivo que atribui significado às suas relações com ambiente e consigo mesmo. As experiências tornam-se significativas para a vida humana em função de um conjunto de habilidades cognitivas que the possibilita perceber, imaginar e interpretar a realidade circundante. A investigação inteligente, conduzida a partir da participação do pensamento e do raciocínio na interação com o ambiente, permite ao sujeito reconstruir as experiências passadas e redirecionar as experiências subsequentes.

A reconstrução da experiência, conduzida por intermédio de situações que suscitem a reflexão e o desenvolvimento do raciocínio, proporciona a construção do conhecimento humano, enriquece o espírito e atribui significação mais profunda à vida. Se o processo de interação não estiver associado a algum elemento intelectual não é possível nenhuma experiência significativa. Contudo, à medida que se manifestam o pensamento e a reflexão na combinação entre o fazer e o sofrer as consequências, aumenta proporcionalmente o valor da experiência. O pensar reflexivo, caracterizado pelo esforço intencional de descobrir as relações específicas entre o que se faz e as consequências, de modo a haver continuidade entre ambas, liberta o pensamento do caráter meramente imediato, sensível e dogmático. A experiência contínua e dirigida reflexivamente dá origem a uma melhor maneira de pensar, auxiliando o indivíduo na condução mais inteligente da vida. Por conta disso, o pensar reflexivo tornou-se, para Dewey, o fim de toda a educação. A experiência significativa, direcionada ao ambiente educacional, visa emancipar os sujeitos da ação meramente rotineira e caprichosa. No âmbito pedagógico, "aprender da experiência é fazer uma associação retrospectiva e prospectiva entre aquilo que fazemos às coisas e aquilo que em consequência essas coisas nos fazem gozar ou sofrer" (DEWEY, 1959a, p. 153).

Ao fundamentar sua teoria educacional, ele adotou a experiência como ponto de partida do processo formativo-educacional humano, a qual será a chave para a solução de problemas ou para a aquisição de novos conhecimentos. O filósofo não aceitou a tese de que o aluno aprende passivamente, na condição de simples espectador. A educação precisaria ser concebida como processo ativo e construtor da experiência humana. O processo educativo deveria levar em conta os dois princípios fundamentais da experiência: o conceito de continuidade e o conceito de interação. Dewey defendeu que a experiência sofre constantes mutações por meio da interação dos sujeitos com o meio. "O princípio de continuidade de experiência toma algo das experiências passadas e modifica de algum modo as experiências subsequentes" (1979, p. 26). Porém, a relação do sujeito com o meio iria afetar para pior ou para melhor as experiências subsequentes. Por assim dizer, o processo educativo exerceria um papel importante na formação de experiências significativas. Caberia ao professor criar meios que promovam o crescimento físico, intelectual e moral dos sujeitos, isto é, ele deveria "ser capaz de julgar quais atitudes são conducentes ao crescimento contínuo e quais lhe são prejudiciais" (DEWEY, 1979, p. 30). 
O princípio da continuidade seria um dos critérios pelo qual se poderia discriminar entre experiências educativas e deseducativas. O problema central da educação alicerçada na experiência estria vinculado ao reconhecimento de situações concretas que conduzem a reconstrução das experiências anteriores, de modo a influir frutiferamente na projeção de novos modos de ação e no aperfeiçoamento das experiências futuras. O processo educativo, segundo a concepção deweyana de educação, é semelhante ao crescimento. A função do professor, enquanto membro mais amadurecido do grupo, seria a de avaliar para quais fins tendem as experiências. $\mathrm{O}$ processo de crescimento, resultante das experiências realizadas em âmbito escolar, poderia promover ou retardar o crescimento geral. A escola propiciaria a construção de experiências educativas quando atribui um direcionamento ao crescimento e prepararia as condições para a ocorrência de novas experiências. No que diz respeito à reconstrução contínua da experiência, Dewey (1959a, p. 110) afirmou: "servimo-nos de nossas experiências pretéritas para construir novas e melhores porvir. Por esta forma, o próprio fato da experiência inclui o processo pelo qual ela se conduz em seu próprio aperfeiçoamento".

O processo de interação provém da relação entre o sujeito e o meio em que está inserido. Nessa relação, os dois polos são ativos, ou seja, um exerce influência sobre o outro. Assim como as experiências dos sujeitos sofrem transformações ao se relacionarem com o mundo externo, num processo de interação, o sujeito também transformaria a realidade externa ao traduzir suas experiências em ações. Seguindo essa lógica, para haver interação no contexto educacional seria preciso que os alunos sejam sujeitos ativos na construção de seus conhecimentos e, como consequência, na reconstrução de suas experiências. Sobre isso, Cunha (2007, p. 105) afirma que "só é realmente conhecimento o que foi organizado para nos habilitar a adaptar o ambiente a nossas necessidades e nossos objetivos e desejos à situação em que vivemos". Na concepção pragmática deweyana, o conhecimento se organiza por meio de situações problematizadoras que envolvem o indivíduo e o ambiente. Isso significa que na escola progressiva o professor cria elementos que venham a superar a apropriação passiva de conteúdos, estimulando a interação dos sujeitos com as pessoas e com as coisas.

O princípio de interação, conduzido com o auxilio de atividades em que os educandos tenham oportunidade de participar e pelas quais todos se sintam responsáveis, confere um sentido educativo a experiência. A utilização de materiais e procedimentos que suscitem a interação permite sustentar a concepção de educação como condição ao crescimento físico, intelectual e moral dos educandos. A falta de adaptação da matéria às necessidades e capacidades dos indivíduos rompe com o princípio da interação ao desmobilizar o desejo dos alunos de continuar a aprender, comprometendo o desenvolvimento de experiências educativas. O desenvolvimento de atividades que estimulam a interação e despertam no aprendiz uma busca ativa por novas ideias, confere aos métodos de ensino e as matérias ensinadas maior eficiência em seu aprendizado. A educação como crescimento está associada à formação para uma vida moral democrática, por meio de medidas que estimulem o pensamento e o intercâmbio de experiências. De acordo com Pagni (2011, p. 56), tal condição "não seria possível sem uma atitude ética e um arranjo social democrático que permitisse a condução inteligente e livre da experiência e que levasse a cabo esse fim da educação, pois somente esses princípios garantiriam um movimento progressivo similar ao do crescimento no plano da história”. 


\section{A educação como condição para a democracia}

De acordo com a filosofia pragmática deweyana, a democracia não seria um fato histórico pretérito, alicerçado em valores morais e em hábitos sociais determinados e/ou conservados pela tradição. Trata-se de um processo político fundado na potencialidade humana e na construção de um modelo formativo-educacional que permita a escola coordenar os fatores da mentalidade que se pretende desenvolver e purificar os costumes sociais existentes, por meio de ações que possibilitem eliminar os aspectos desvantajosos e os fatores indesejáveis do ambiente comum, concedendo aos educandos oportunidades para fugir às limitações do grupo social em que nasceu. Nesses termos, a democracia é concebida como um processo a ser construído de forma planejada e intencional, contrapondo-se às decisões determinísticas e à sujeição dos seres humanos a formas de vida construídas historicamente. Em função das influencias e limitações impostas aos indivíduos pelos vários meios sociais - incluindo, a família, a rua, o comércio e os meios religiosos -, nenhuma sociedade torna-se democrática espontaneamente. $\mathrm{O}$ ambiente social, caracterizado por diferentes grupos, costumes, tradições, aspirações e espécies de governo, exerce um influxo formador nas disposições ativas dos indivíduos, podendo estimular ou inibir a construção de experiências democráticas. A vida em família, por exemplo, embora costumeiramente cultive em seu seio atitudes de afeto e auxílio mútuo, pode caracterizar-se por grande segregação, desconfiança e ciúme em relação aos estranhos a ela. Em tese, Dewey (1959a, p. 89) afirma que "toda educação ministrada por um grupo tende a socializar seus membros, mas a qualidade e o valor da socialização dependem dos hábitos e aspirações do grupo".

Por essa razão, a edificação de uma sociedade democrática não se limita a mera reprodução dos traços que se encontram na realidade. A falta de critérios formativos e a espontaneidade com que se constituem os valores, os costumes e os interesses no interior dos diferentes grupos sociais, podem favorecer o surgimento de autocracias, sistemas excludentes e ditatoriais. A formação espiritual mais profunda e sólida requer ações formativas que viabilizem a eliminação dos traços indesejáveis das formas de vida social existentes e estimulem o desenvolvimento de um meio social ampliado e melhor equilibrado do que aquele pelo qual os indivíduos, abandonados a si mesmos, seriam provavelmente influenciados. Uma sociedade indesejável é a que interna e externamente cria barreiras para o livre intercâmbio e comunicação da experiência humana, provocando a instrumentalização das ações humanas e inibindo a reconstrução de experiências pessoais e sociais. Diferentemente das comunidades estáticas, que adotam como medida de valor a manutenção dos costumes estabelecidos, as comunidades progressivas "se esforçam por modelar as experiências dos jovens de modo que, em vez de reproduzirem os hábitos dominantes, venham a adquirir hábitos melhores, de modo que a futura sociedade adulta seja mais perfeita que as suas próprias sociedades atuais" (DEWEY, 1959a, p. 85).

A sociedade torna-se democrática quando os diferentes grupos sociais são capazes de intercambiar experiências entre si de modo livre e plural. A falta de entrelaçamento entre as várias atividades da vida e o isolamento provocado pela divisão da sociedade em classes dificulta a mútua comunicação de experiências. A inexistência de interação entre a classe privilegiada e a classe submetida impede a endosmose social 
e o compartilhamento tácito de interesses. A experiência de cada uma das partes perde em significação quando não existe o livre e razoável intercâmbio entre os grupos sociais, pois se limitam a reproduzir os traços que se encontram na realidade, em vez de objetivar a reorganização e o progresso por meio de relações mais amplas e plurais. $\mathrm{O}$ isolamento tende a gerar no interior do grupo a rigidez e a institucionalização formal da vida, favorecendo o surgimento de ideais estáticos e egoístas. A reconstrução contínua dos valores, costumes e interesses sociais requer o desenvolvimento de um processo formativo calcado em ações e métodos que viabilizem a realização de uma forma de vida social onde os interesses se conectam mutuamente. Para Dewey (1959a, p. 87), "uma sociedade que, não somente muda, mas que, também, para estimulá-la, faz da mudança um ideal, terá normas e métodos educativos diferentes dos de outras que aspire meramente à perpetuação de seus próprios costumes". A educação conscientemente planejada pode eliminar manifestos males sociais na medida em que favorecer a reconstrução contínua da experiência humana. Ao estimular o entrelaçamento de experiências e ao coordenar, na vida mental de cada indivíduo, as diversas influências provindas dos vários meios sociais, a escola torna-se um ambiente fortalecedor e integrador das diferentes experiências e formas de vida, conduzindo-os ao sentido e compreensão real das coisas mais complexas.

A teoria da ação proposta por Dewey possui um conjunto de conhecimentos de suma importância para a construção de experiências democráticas. A democracia como forma de vida constitui-se a partir de vivências e situações que suscitem a interação e a comunicação livre entre os homens. De acordo com Pagni (2011, p. 58), o desenvolvimento de experiências democráticas se pauta "na recusa de todo princípio de autoridade externa e do autoritarismo [...]. Assim a democracia seria um modo ético de vida a ser experimentado e vivido pelo indivíduo como uma atitude geral e aberta frente à vida e ao mundo que, na educação, encontraria ocasião de ser experimentada e formada". A vida moral democrática ganha um sentido mais preciso na educação na medida em que os conteúdos e métodos viabilizem o intercâmbio de experiências, a livre comunicação e a convivência com a diferença e a pluralidade existente. $\mathrm{O}$ processo educacional de caráter democrático está associado ao desenvolvimento de experiências educativas, por meio de ações que estimulem a cooperação mais livre entre os membros do grupo, de modo a promover o progresso moral necessário a sociedade, tornando-a cada vez mais inclusiva. A educação torna-se um processo social de caráter democrático na medida em que é estabelecido um estado de cooperação entre os membros envolvidos. Porém, ao professor, "como membro mais amadurecido do grupo, cabe-lhe a responsabilidade especial de conduzir as interações e intercomunicações que constituem a própria vida do grupo, como comunidade" (DEWEY, 1979, p. 54 - 55).

A democracia está vinculada ao aprimoramento contínuo da vida social por meio do intercâmbio de experiências e das disputas entre múltiplas concepções de vida ou de filosofia. A edificação da sociedade democrática efluiu de um conjunto de fatores conjugados historicamente, incluindo: o desenvolvimento da indústria, as atividades econômicas e comerciais, as viagens, as migrações, as telecomunicações e o domínio das ciências. A atuação desses fatores colocou as nações a as classes sociais em íntimas e perceptíveis conexões recíprocas. A modernidade transgrediu a relativa homogeneidade concernente aos tempos antigos, pois, embora existissem várias socie- 
dades, a diversidade de grupos era estritamente geográfica. A aproximação entre povos e classes que dantes viviam isolados propiciou a ampliação da área dos interesses compartilhados e a libertação de uma maior diversidade de capacidades pessoais. Em tese, Dewey (1959a, p. 22) salientava que "no interior de uma sociedade moderna, malgrado sua nominal unidade política, existem provavelmente mais comunidades e diversidade de costumes, tradições, aspirações e espécies de governo ou de influência do que existiram em todo um continente em uma era remota". O compartilhamento de interesses comuns (reciprocidade) entre os membros de uma comunidade e a interação entre as nações, alavancado sobremaneira pelas transformações ocorridas na modernidade, proporcionaram a contínua reconstrução da experiência social e a constituição de sociedades plurais e democráticas.

A sociedade democrática viabiliza a interação e a cooperação mais livre entre os indivíduos, de modo a aprimorar as formas de vida social para que elas se tornem melhor do que são no presente. A democracia como forma de vida cultiva o respeito à diversidade humana e repudia todo princípio de autoridade externa e do autoritarismo. "Uma sociedade móvel cheia de canais distribuidores de todas as mudanças ocorridas em qualquer parte, deve tratar de fazer que seus membros sejam educados de modo a possuírem iniciativa individual e adaptabilidade". (DEWEY, 1959a, p. 94). Quanto ao aspecto formativo, a escola deve proporcionar a todos um meio social novo e mais vasto mediante a convivência de diferentes raças, religiões e de costumes dessemelhantes. A falta de experiências conjuntas, estabelecidas mediante associações e/ou comunicação com as diferentes formas de vida, permite que o isolamento, o exclusivismo e o interesse particular e imediato se coloquem acima da interação coletiva.

\section{Considerações finais}

A filosofia da educação proposta por Dewey indica que a construção de uma sociedade democrática requer o desenvolvimento de uma forma de vida associada, de experiência conjunta e mutuamente comunicada. A democracia não se reduz a uma forma de governo. O ideal democrático está associado à consecução de um modo ético de vida a ser experimentado e vivido pelos indivíduos como uma atitude geral e aberta a vida e ao mundo. $\mathrm{O}$ aprimoramento da vida social pode ser alcançado por meio da capacidade humana de desenvolver uma vida propensa ao diálogo e entrelaçada com as diferenças humanas existentes. A convivência com as diferentes formas de vida estimula os indivíduos a variar seus atos e lhes possibilita uma diversidade a mais de estímulos, de modo a ampliar seus campos de interesse. A reciprocidade coletiva com outros grupos permite-os refinar suas experiências e julgá-las reflexivamente, escolhendo para si um modo inteligente de conduzir as suas próprias vidas. "Uma sociedade é democrática na proporção em que prepara todos os seus membros para com igualdade aquinhoarem de seus benefícios e em que assegura o maleável reajustamento de suas instituições por meio da interação das diversas formas de vida associada" (DEWEY, 1959a, p. 106).

A escola, por sua vez, torna-se o ambiente formativo responsável pela construção de experiências educativas, de modo a viabilizar o aperfeiçoamento contínuo da sociedade. No contexto das sociedades plurais, os sistemas educacionais têm a função 
de viabilizar as condições necessárias ao aprendizado da democracia, bem como à formação de uma atitude ética. A educação de cunho progressivo visa promover, a partir de experiências educativas, um tipo de interação mais livre entre os homens. Os princípios e/ou referenciais que regem os processos educacionais não podem ser estabelecidos de maneira fixa e definitiva ou de forma que traduzam a submissão do indivíduo à ordem social e econômica. Dado que a realidade é algo em permanente movimento, a edificação da sociedade democrática requer o desenvolvimento de atitudes de respeito à pluralidade e a liberdade individual em prol do bem-estar coletivo. $\mathrm{Na}$ medida em que é estabelecido um estado de cooperação entre os membros envolvidos no processo de ensino-aprendizagem, a educação torna-se um processo social comprometido com a construção de experiências democráticas. Porém, ao professor, "como membro mais amadurecido do grupo, cabe-lhe a responsabilidade especial de conduzir as interações e intercomunicações que constituem a própria vida do grupo, como comunidade" (DEWEY, 1979, p. 54 - 55).

Diferentemente das sociedades divididas em castas, cujos processos educacionais preocupam-se verticalmente com a formação da classe dirigente, numa sociedade democrática apregoa-se a reciprocidade cooperativa e o entrelaçamento entre as diferentes formas de vida por meio de práticas educacionais que estimulem a interação e o desenvolvimento do pensamento reflexivo. Nas sociedades democráticas aprender a pensar constituí uma das principais tarefas da educação, pois as pessoas que pensam são cautelosas, circunspectas e capazes de transgredir os hábitos dominantes. As sociedades que almejam a formação de indivíduos democráticos e fazem da transformação um ideal de vida necessitam ter normas e métodos diferentes daqueles adotados em sociedades que não aspiram semelhantes ideias. A educação tem a grande tarefa de possibilitar a realização máxima do crescimento do ser humano. Segundo Dewey (1959a, p. 85-86), a educação conscientemente praticada pode eliminar manifestos males sociais fazendo os jovens seguir caminhos alternativos, além de tornar-se um instrumento para realizar as mais belas esperanças humanas. O crescimento intelectual e o respeito à diversidade humana somente são possíveis pelo exercício de uma vida reflexiva. A educação progressiva, calcada no princípio da interação e na construção de experiências reflexivas, favorece a superação da dicotomia entre indivíduo e sociedade, pois a efetivação da democracia depende da plena satisfação do indivíduo mediante o diálogo e a cooperação entre todos os envolvidos.

\section{Referências}

CUNHA, Marcos Vinícius da. Democracia e educação: capítulos essenciais. São Paulo: Ática, 2007.

DEWEY, John. Democracia e educação: introdução à filosofia da educação. 3 ed. Trad. Godofredo Rangel e Anísio Teixeira. São Paulo: Nacional, 1959a.

DEWEY, John. Como Pensamos: como se relaciona o pensamento reflexivo com o processo educativo, uma reexposição. 3 ed. São Paulo: Companhia Nacional, 1959 b.

DEWEY, John. Experiência e educação. 3 ed. São Paulo: Nacional, 1979.

PAGNI, Pedro. Leitura sobre as contribuições de John Dewey para a educação. In: FÁVERO, Altair A.; TONIETO, Carina (Orgs.). Leituras sobre John Dewey e a educação. Campinas: Mercado de Letras, 2011. P. 43-60. 
* Professor doutor da Universidade de Passo Fundo, Passo Fundo, Rio Grande do Sul, Brasil.

** Professor da Prefeitura Municipal de Tapejara, Tapejara, Rio Grande do Sul, Brasil.

\section{Correspondência}

Altair Alberto Fávero - Universidade de Passo Fundo, Instituto de Filosofia e Ciências Humanas, Filosofia. Campus I - São José. CEP: 99001-970. Passo Fundo, Rio Grande do Sul, Brasil..

E-mail: altairfavero@gmail.com - diego_bechi@yahoo.com.br

Recebido em 29 de outubro de 2016

Aprovado em 19 de dezembro de 2016

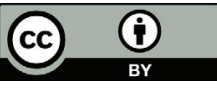

This work is licensed under a Creative Commons Attribution 4.0 International (CC BY 4.0). 
